\title{
Editorial
}

\section{A Política Nacional de Vigilância em Saúde}

\author{
doi: 10.5123/S1679-49742018000300018
}

\section{The National Health Surveillance Policy}

\section{La Política Nacional de Vigilancia en Salud}

$\mathrm{E}$ m 12 de julho de 2018, foi instituída a Política Nacional de Vigilância em Saúde (PNVS), por meio da Resolução no 588/2018 do Conselho Nacional de Saúde (CNS). ${ }^{1}$ Trata-se de documento inédito, norteador do planejamento das ações de vigilância em saúde nas três esferas de gestão do Sistema Único de Saúde (SUS), caracterizado pela definição das responsabilidades, princípios, diretrizes e estratégias dessa vigilância.

A PNVS incorporou diretrizes e propostas debatidas e aprovadas durante a $1^{a}$ Conferência Nacional de Vigilância em Saúde (CNVS), realizada em Brasília de 27 de fevereiro a 2 de março de 2018, que foi tema de editorial previamente publicado na Epidemiologia e Serviços de Saúde: revista do Sistema Único de Saúde do Brasil. ${ }^{2}$ o evento, organizado pelo Conselho Nacional de Saúde (CNS) com o apoio da Secretaria de Vigilância em Saúde do Ministério da Saúde (SVS/MS), contou com a participação de 1.820 conferencistas provenientes de todas as Unidades da Federação. Foi a primeira ocasião, desde a promulgação da Constituição Federal de 1988, em que a vigilância em saúde foi amplamente debatida por trabalhadoras e trabalhadores, gestoras e gestores da Saúde, membros da academia, e também por usuárias e usuários do SUS. 0 Relatório Final da $1^{\text {a }}$ CNVS registra, com riqueza de texto e imagens, os debates realizados durante esse grandioso evento. ${ }^{3}$

A PNVS é definida como uma política pública de Estado e função essencial do SUS, de caráter universal, transversal e orientadora do modelo de atenção à saúde nos territórios. Sua efetivação depende de seu fortalecimento e articulação com outras instâncias do sistema de saúde, enquanto sua gestão é de responsabilidade exclusiva do poder público.

Na PNVS, a Vigilância em Saúde é entendida como processo contínuo e sistemático de coleta, consolidação, análise de dados e disseminação de informações sobre eventos relacionados à saúde, visando o planejamento e a implementação de medidas de saúde pública, incluindo a regulação, intervenção e atuação em condicionantes e determinantes da saúde, para a proteção e promoção da saúde da população, prevenção e controle de riscos, agravos e doenças. ${ }^{1}$

A PNVS incide sobre todos os níveis de atenção à saúde, abrange todos os serviços de saúde - públicos e privados -, assim como estabelecimentos dedicados à produção e circulação de bens de consumo e tecnologias relacionadas. Alinhada ao conjunto de políticas de saúde do SUS, a PNVS salienta a necessidade da articulação dos saberes, processos e práticas relativos à vigilância epidemiológica, vigilância em saúde ambiental, vigilância em saúde do trabalhador e vigilância sanitária, haja vista a transversalidade das ações da vigilância sobre o processo saúde-doença. ${ }^{1}$

A PNVS apresenta, como responsabilidades partilhadas entre União, estados, Distrito Federal e municípios: assegurar a oferta de ações e de serviços de vigilância em saúde, estabelecer e garantir a articulação entre os setores responsáveis pelas políticas públicas, desenvolver estratégias para identificar e controlar situações que resultem em risco de agravos à saúde, entre outras. ${ }^{1}$

Da mesma forma, o financiamento das ações da vigilância em saúde deve ser garantido de forma tripartite. A PNVS determina que esse financiamento seja específico, permanente, crescente e suficiente para assegurar os recursos e tecnologias necessários ao cumprimento do papel institucional das três esferas de gestão do SUS, ademais de contribuir para 0 aperfeiçoamento e melhoria da qualidade de suas ações. ${ }^{1}$ 
O documento final da PNVS foi consolidado pela Comissão Instersetorial de Vigilância em Saúde do Conselho Nacional de Saúde. Sua origem, marcada pela participação popular na implantação e consolidação do SUS, é evidente em seu texto quando situa o Conselho de Saúde como protagonista dos processos de avaliação e monitoramento da PNVS. ${ }^{1} 0$ tão extenso quanto diverso conjunto de pessoas que contribuíram para a construção da PNVS estará atento, envolvido não somente na efetivação dessa política como também na defesa permanente do SUS. 0 sucesso da Política Nacional de Vigilância em Saúde está atrelado ao fortalecimento do Sistema Único de Saúde, o maior sistema público e universal de saúde do mundo, importante conquista da população brasileira, que tem a saúde como um de seus direitos fundamentais. ${ }^{4}$

\section{Osnei Okumoto'}

Sônia Maria Feitosa Brito'

Leila Posenato Garcia²

${ }^{1}$ Ministério da Saúde, Secretaria de Vigilância em Saúde, Brasília, DF, Brasil

${ }^{2}$ Instituto de Pesquisa Econômica Aplicada, Diretoria de Estudos e Políticas Sociais, Brasília, DF, Brasil

\section{Referências}

1. Brasil. Ministério da Saúde. Conselho Nacional de Saúde. Resolução MS/CNS nº 588, de 12 de julho de 2018. Fica instituída a Política Nacional de Vigilância em Saúde (PNVS), aprovada por meio desta resolução. Diário Oficial da República Federativa do Brasil, Brasília (DF), 2018 ago 13; Seção 1:87.

2. Garcia LP, Duarte E. $1^{a}$ Conferência Nacional de Vigilância em Saúde: marco para a construção da Política Nacional de Vigilância em Saúde. Epidemiol Serv Saúde. 2018;27(2):e20180002. doi: 10.5123/s1679-49742018000200020.

3. Ministério da Saúde (BR). Conselho Nacional de Saúde. $1^{a}$ conferência nacional de vigilância em saúde: relatório final [Internet]. Brasília: Ministério da Saúde; 2018 [citado 2018 out 25]. 110 p. Disponível em: https://drive.google.com/ file/d/1dI4F1e03LKCsLRF7h00XzxC8VCVkRZkc/view

4. Brasil. Presidência da República. Casa Civil. Constituição da República Federativa do Brasil de 1988 [Internet]. Brasília: Senado Federal; 1988. Disponível em: http://www.planalto.gov.br/ccivil_03/Constituicao/Constituicao.htm 